\title{
O USO DAS CARTAS TERAPÊUTICAS NA PRÁTICA CLÍNICA
}

\author{
Ludoana Pousa Corrêa de Paiva* \\ Emerson Fernando Rasera**
}

\section{Resumo}

Considerando a escassez de estudos sobre o uso de cartas terapêuticas na literatura nacional, este artigo busca promover o debate sobre as suas potencialidades. Assim, apresentamos as cartas terapêuticas como um recurso para a prática clínica, sendo entendidas, ao mesmo tempo, como uma forma de documentação e de intervenção terapêutica. A partir de uma revisão da literatura, contextualizamos o desenvolvimento das cartas terapêuticas na clínica, explicitando sua história, usos e funçôes. Seguindo uma perspectiva narrativa, descrevemos as definiçóes, tipos, princípios gerais e recomendaçôes práticas para a redação de cartas pelos terapeutas. Finalizando, enfatizamos a importância de uma prática epistemologicamente orientada e a necessidade de uma análise das implicaçóes do uso das cartas no contexto brasileiro.

Palavras-chave: cartas terapêuticas; terapia narrativa; prática clínica.

\begin{abstract}
THE USE OF THERAPEUTIC LETTERS IN THE CLINICAL CONTEXT

Considering the scarcity of studies about the use of therapeutic letters in the national literature, this article seeks to promote the debate on its potential. Thus, we present the therapeutic letters as a resource for clinical practice, which is understood, at the same time, as a form of documentation and a therapeutic intervention. From a review of the literature, we contextualize the development of the therapeutic letter in clinical settings, explaining its history, uses and functions. Based on a narrative perspective, we describe the definitions, types, general principles and practical recommendations for the letter-writing by therapists. Finally, we emphasize the importance of an

* Universidade Federal de Uberlândia, Minas Gerais, MG, Brasil. E-mail: ludoana@ hotmail.com.

** Universidade Federal de Uberlândia, Minas Gerais, MG, Brasil. E-mail: emersonrasera@ gmail.com.
\end{abstract}


epistemologically oriented practice, and the need for an analysis of the implications of the use of letters in the Brazilian context.

Keywords: therapeutic letters; narrative therapy; clinical practice.

\section{Introdução}

As cartas terapêuticas têm se apresentado como um recurso produtivo no trabalho clínico, na literatura internacional, porém pouco se tem pesquisado sobre esse tema no contexto brasileiro. Buscando promover o debate sobre o uso de cartas na prática clínica, este artigo tem por objetivo caracterizar os seus contextos de uso, os diferentes formatos, os procedimentos utilizados, bem como explorar o contexto epistemológico que sustenta sua utilização, especialmente aquele vinculado à terapia narrativa. Esperamos, assim, oferecer uma perspectiva pragmática a todos aqueles interessados em lançar mão desse recurso e, ao mesmo tempo, combater uma leitura tecnicista sobre o uso de cartas, fundamentando-o e situando-o no panorama das contribuiçóes narrativas no campo da psicoterapia.

\section{As cartas terapêuticas na prática clínica: de, para e entre pacientes e terapeutas}

A comunicação escrita no âmbito da prática clínica tem sido utilizada há muitos anos. Em uma leitura histórica, segundo Moules (2000), as primeiras descriçóes desta prática foram feitas na década de 1940 por Allport, Landsman, Messiger e Farber, seguidas da experiência de Burton e Ellis, na década de 1960, e por Wagner, na década de 70. Contudo, segundo outros autores, tal como Hunt, Schochet e King (2005), o uso de cartas na terapia, pelo qual o terapeuta se comunica com o paciente, é ainda mais antigo. Eles apontam que Freud foi o primeiro terapeuta a escrever cartas para seus clientes, com o intuito de responder sobre questóes transferenciais.

Atualmente, diferentes pesquisas têm sido realizadas sobre as formas de se utilizar a linguagem escrita na clínica. Apesar dos variados termos e descritores associados à pratica da escrita na clínica, em uma análise da literatura sobre os contextos de uso das cartas, podemos identificar três modos predominantes: 1) o paciente que escreve cartas seja para si, para outras pessoas ou para determinado objeto; 2) o terapeuta e o paciente que escrevem entre si; e 3) o terapeuta que escreve cartas para o paciente. 
No que se refere às cartas escritas pelos clientes, percebemos que esta é a forma preferida pelos terapeutas, sendo amplamente utilizada em contextos individuais, familiares e grupais. Nesse campo, em um trabalho pioneiro na década de 1960, Widroe e Davidson (conforme citado por Pyle, 2009) relatam um estudo com 12 participantes no qual se observou que a partir do processo de leitura e releitura se promovia uma maior observação em relação ao uso de suas palavras e do conteúdo emocional empregado. No contexto da saúde, Brouwers (2001) destaca o uso das cartas em tratamento de grupos de mulheres com bulimia. Nesse contexto, as mulheres escrevem cartas para a comida, e são apontadas quatro justificativas para seu uso: 1) cartas lidas em voz alta para o grupo aumentam a coesão grupal; 2) na escuta do relato, as pessoas podem considerar alternativas, sendo encorajadas a tomar atitudes mais saudáveis; 3) o insight é estimulado, promovendo a reflexão da função da bulimia na vida dessas mulheres e 4) há um aumento das discussóes que envolvem o tema bulimia, tais como apoio familiar, abuso sexual, imagem do corpo, perfeccionismo e autoestima. Também Kress, Hoffman e Thomas (2008), que trabalham no contexto de aconselhamento a vítimas de abuso sexual, enfocando a escrita realizada pelos clientes, apontam que a construçáo das cartas tem perspectiva no futuro e sua funçáo é atuar como um veículo para a criação da mudança, o que inclui forças individuais, pensamentos motivadores e conselhos.

Além disso, alguns autores trabalham as cartas na terapia como correspondências entre o terapeuta e o cliente. Nesse âmbito, Pyle (2004) destaca Alston, que na década de 1950 foi um dos primeiros a utilizar essa prática ao cuidar durante dois anos de uma paciente com tuberculose e trocar com ela cerca de oitocentas cartas. Mais recentemente, Yeung, Chang e Chau (2003) pesquisaram um grupo de crianças em Hong Kong, com idade entre 10 e 14 anos, que escrevem cartas com o objetivo de criarem novos significados, em um contexto de problemas com familiares, amigos e escola. A correspondência que ocorre entre as crianças e o terapeuta se faz útil à medida que oferece feedback informal para as crianças. Já Augusta-Scott (2007) realiza um estudo relativo a cartas trocadas entre ela, enquanto terapeuta, e um homem preso por violentar sexualmente sua filha. Por intermédio das cartas, ela buscou focar no processo de reautoria da identidade desse homem, de forma que possibilitasse a ele se responsabilizar pelo abuso e promover relacionamentos respeitosos e cuidadosos, bem como tentar criar uma audiência com outras pessoas para sustentar sua identidade de reautoria.

No que se refere às cartas escritas por terapeutas para pacientes, as pesquisas são em pequeno número, mas apontam um interesse para a área (Vidgen \& Williams, 2001), ganhando destaque nos últimos dez anos. Apesar de não encontrarmos 
nenhum artigo relativo ao uso de cartas terapêuticas na literatura nacional, vários artigos começam a se destacar na literatura internacional. Os artigos disponíveis abrangem uma variada gama de possibilidades, incluindo diferentes campos disciplinares, contextos de uso e populaçóes clínicas. Dessa forma, no que se refere aos campos disciplinares/profissionais, as cartas terapêuticas são utilizadas na terapia familiar (Vidgen \& Williams, 2001), na terapia em grupo (Chen, Noosbond \& Bruce, 1998), no aconselhamento (Paré \& Rombach, 2003) e na prática da equipe de enfermagem (Erlingsson, 2009). Os diferentes contextos de uso incluem desde a clínica psicoterápica em geral (Pyle, 2009) e as consultas psiquiátricas (Couper \& Harari, 2004), passando pelas escolas com os adolescentes, pais e professores (Oliver, Nelson, Cade \& Cueva, 2007), até o aconselhamento breve nas empresas (Wright, 2005). As cartas terapêuticas também foram utilizadas de maneira efetiva com diferentes populaçóes, seja com pessoas que sofrem distúrbios alimentares (Davidson \& Birmingham, 2001), com experiências traumáticas passadas (Esterling, L'Abate, Murray \& Pennebaker, 1999), com adolescentes e suas famílias (Goldberg, 2000) e com pacientes em crise (Tubman, Montgomery \& Wagner, 2001).

No contexto das cartas escritas pelos terapeutas, White e Epston (1990) convidam os terapeutas a escreverem aos seus pacientes. As cartas terapêuticas, na perspectiva da terapia narrativa, se afastam do uso convencional da escrita na clínica, na qual é entendida como uma escrita administrativa e burocrática, e buscam alcançar âmbitos relacionais, relativos aos acontecimentos presentes na sessão, às possíveis descriçóes que convidam tanto paciente quanto terapeuta ao futuro, bem como às reflexóes concernentes ao processo terapêutico.

Assim, a partir das contribuiçóes da terapia narrativa no fomento ao uso das cartas terapêuticas, descreveremos a seguir as particularidades concernentes às formas de linguagem privilegiadas em sua redação, seus objetivos, bem como os diversos formatos e usos das cartas. Ressaltamos que a ênfase será nas cartas escritas pelos terapeutas, como um instrumento de documentação e intervenção terapêuticas.

\section{As cartas escritas pelos terapeutas em uma perspectiva narrativa}

As cartas podem ser escritas a partir de diferentes referenciais teóricos e, consequentemente, podem seguir procedimentos e ter objetivos variados. Buscaremos, a seguir, descrever a pragmática das cartas na prática clínica a partir de uma perspectiva narrativa. Assim, apresentaremos o contexto teórico, as defini- 
ções e funções das cartas, seus tipos, princípios gerais e recomendações práticas para a sua escrita.

\section{Contexto teórico, definição e funçóes das cartas}

No contexto intelectual da Terapia Narrativa ${ }^{1}$, as cartas ganham identidade e seu uso é enfatizado e teoricamente justificado, tendo um lugar privilegiado no processo psicoterápico. Segundo White e Epston (1990, p. 50), proponentes dessa teoria terapêutica, essa importância se dá pois, "em nossa cultura, o uso da tradição escrita em terapia promove formalização, legitimação e continuidade dos conhecimentos populares locais, da autoridade independente das pessoas e a criação de um contexto para o surgimento de novos descobrimentos e possibilidades".

As cartas terapêuticas, diferentemente das cartas sociais, têm como foco o contexto, conteúdo, intençóes e efeitos causados no paciente e no terapeuta (Oliver et al., 2007). São cartas mais literárias do que diagnósticas, mais expóem situaçóes e possibilidades do que explicam algo. Na Terapia Narrativa, as cartas são terapêuticas quando são centradas no cliente, quando as informaçóes contidas são originadas dos encontros com o paciente, quando os eventos psicologicamente relevantes conseguem ser interligados, quando conexóes entre pessoas são feitas e mantidas, quando registram o progresso do paciente e quando voltam o olhar para o futuro com esperança e realismo (Goldberg, 2000).

Em uma perspectiva narrativa, a ideia de que as pessoas, no intuito de darem sentido à sua existência e legitimar açóes, organizam suas histórias em um fluxo contínuo e sequencial fundamenta o uso das cartas terapêuticas. White e Epston (1990) sugerem as cartas como um instrumento que, por meio da palavra escrita, proporciona sentido de coerência, ao mesmo tempo que possibilita reflexões sobre as experiências em uma dimensão temporal.

Entre suas diversas funçóes, as cartas buscam ligar acontecimentos, encontros, conectando o passado com o presente e com as possibilidades futuras, provendo além de uma sequencia narrativa uma ponte entre as sessóes (Chen et al., 1998; Paré \& Rombach, 2003). Elas realçam progressos, solidificam mudanças positivas, sustentam os significados criados durante as sessóes terapêuticas, apontam outras direções possíveis, proveem suporte emocional, sustentam competências e criam reflexividade, reforçando a habilidade do cliente em trabalhar seus problemas (Augusta-Scott, 2007; Freeman, Epston \& Labovits, 2001; Payne, 2006). 
As cartas possibilitam aos clientes um espaço de distanciamento, pois perduram no tempo, permitem que eles reflitam sobre os eventos durante a terapia, bem como transmitem as ideias de uma forma permanente, podendo ser consultadas a qualquer tempo (Davidson \& Birmingham, 2001). De forma semelhante, as questóes reflexivas presentes na carta convidam o cliente a um território inabitado, onde ele pode buscar resolver seus problemas e coconstruir novas realidades. Além disso, como as competências dos clientes são acentuadas nas cartas terapêuticas, pois estas promovem uma visão não-patologizante do problema, torna-se possível propiciar mudanças por um longo período a partir desse instrumento interventivo, mudanças que podem ser testemunhadas pelos membros da família, ou outras pessoas que tenham importância na vida do cliente (Paré \& Rombach, 2003).

As cartas terapêuticas também auxiliam o terapeuta seja a entrar no mundo do protagonista e propiciar um contexto de colaboração, seja a criar ideias novas e originais (Freeman et al. 2001). Isto é possível, pois, como Rombach (2003) aponta, quando utiliza as nomenclaturas diagnósticas o terapeuta recebe um convite inevitável para uma visão de déficit nas pessoas. Porém com a escrita das cartas ocupa-se um lugar de compreensão e de legitimação de mudanças, o que possibilita uma substituição de evoluçóes patológicas por uma alteridade positiva. Assim, apesar de a carta mostrar-se de extrema importância para quem a recebe, o ato de escrevê-la também oferece um espaço de reflexão para o terapeuta sobre o que foi vivenciado durante a sessão. Ao redigir a carta, o terapeuta tem a oportunidade de se questionar se existem outras alternativas nas quais ele poderia coordenar suas açóes. Logo, a responsividade com o outro pode ser pensada: o jeito com que eu convido meu cliente a conversar está sendo útil? Esse é um jeito que amplia ou restringe as histórias? Minhas questóes geram respostas ou novas perguntas? O terapeuta ganha um espaço para organizar suas ideias, questionar falas e elaborar perguntas que poderão ser colocadas em pauta em sessóes posteriores. Dessa forma, as cartas tornam-se uma extensão dos diálogos desenvolvidos no atendimento e uma ferramenta útil para que o profissional amplie seus conhecimentos sobre a terapia (Paré \& Rombach, 2003).

\section{Tipos de cartas}

White e Epston (1990) apresentam exemplos práticos de material escrito na clínica que atende a objetivos múltiplos. Eles denominam esse tipo de terapia, na qual ocorre a presença de material escrito, por "terapia relatada", que engloba 
tanto cartas quanto demais documentos, tais como certificados, declaraçóes e autocertificados. Tais cartas são apresentadas tendo a possibilidade de serem escritas tanto pelo terapeuta para o paciente, quanto pelo terapeuta em conjunto com o paciente e, por fim, escrita pelo paciente e endereçada a remetentes diversos.

Nessa perspectiva mais ampla das cartas como documentos clínicos, elas podem ser de vários tipos: a) Cartas de convite, que são frequentes na vida cotidiana e utilizadas no contexto profissional quando o terapeuta acredita ser importante incluir na terapia pessoas que se encontram relutantes em participar da mesma; b) Cartas de despedida, que são escritas para oportunizar às pessoas que exercem papéis não desejados que se despeçam deles, ficando livres para ocupar outros lugares; c) Cartas de seguimento, em que, ao final da terapia, uma carta escrita pelo terapeuta é entregue ao paciente para que seja aberta ao fim de seis meses no intuito de propor uma revisão, um seguimento após esses seis meses; d) Cartas de recomendação, nas quais o terapeuta pode apontar percepções para a família que são importantes para a pessoa que está sendo atendida; e) Cartas para ocasióes especiais que podem ser utilizadas em caso de pacientes que, por algum motivo, não foram à terapia e f) Cartas breves, que podem incluir reflexóes após a sessão, busca de informaçóes a respeito da vida e relaçóes das pessoas e convocar um público que mantenha e elabore novas histórias de maneira mais intensa.

Essa variedade de tipos de cartas aponta como elas podem ser utilizadas em diferentes momentos do processo terapêutico, destinadas a participantes variados e buscando alcançar objetivos específicos. Dependendo de cada uma destas circunstâncias, a carta pode adquirir formatos particulares. Contudo, independente do momento em que é utilizada, deve se orientar por alguns princípios gerais que potencializam sua efetividade e seu poder de convidar à mudança.

\section{Principios para a redaçâo das cartas}

Considerando o poder performático das palavras, ou seja, a capacidade da linguagem de construir realidades e, consequentemente, de os documentos clínicos adquirirem um status de "verdade", uma atenção especial deve ser dada ao modo de usar a linguagem na construção das cartas. A partir dessa preocupação, Chen et al. (1998, p. 405) propóem um modelo que "destaca a linguagem como agente ativo de mudança na documentação do cliente. Esse modelo tem como objetivo democratizar o sistema de documentação do cliente e expandir sua função em uma intervenção nela mesma”. Esse modelo engloba quatro princípios: 
a desconstrução do self subjugado, a busca por exceçôes, manter uma postura de não saber e internalizar o agenciamento pessoal.

A "desconstrução do self subjugado" diz respeito a desconstruir o autoconceito negativo desenvolvido pelo cliente. As pessoas que procuram atendimento comumente estão com a vida saturada por problemas e se descrevem como "ineficazes e sem recursos". Essas pessoas percebem seus problemas como patologias que surgem delas mesmas e dizem não conseguir encontrar maneiras de agir com seus próprios saberes. As cartas terapêuticas auxiliarão essas pessoas a reformular o relacionamento que elas têm com seus problemas a partir de uma "linguagem des-patologizante" (Chen et al., 1998, p. 406). Para que esse processo ocorra, o terapeuta utilizará de recursos da Terapia Narrativa, tais como a externalização do problema (separar a vida da pessoa da vida do problema), a personificação do problema (externalizar o problema com características humanas) e a contextualização do problema (recorrer aos discursos sociais e culturais que sustentam o problema na vida da pessoa).

O princípio da "busca por exceçôes" envolve a identificação dos "acontecimentos extraordinários" e a promoção de uma linguagem de transição. Um acontecimento extraordinário inclui "toda gama de acontecimentos, sentimentos, intenções, pensamentos, ações, etc., que têm uma localização histórica, presente ou futura" (White \& Epston, 1990, p. 32). Para tanto, exceçóes são ressaltadas em narrativas desencorajadoras e, para responder a essas exceçóes, os recursos do cliente e seus pontos fortes, anteriormente desapercebidos, são enfatizados. Ao promover uma linguagem de transição, as exceçóes são descritas a partir de uma linguagem que acentua as relaçóes de desenvolvimento do cliente com o problema. Dessa forma, o documento terapêutico aponta o movimento de linguagem de uma postura para outra, ilustrando o desenvolvimento da interligação entre a ação do cliente e seu resultado.

O princípio de "manter uma postura de não-saber" requer que o terapeuta deixe em suspenso o seu conhecimento profissional acumulado, mantenha uma postura de curiosidade genuína, não entenda rápido demais a história apresentada, coloque em dúvida o que parece já saber e evite julgamentos e generalizaçóes. Dessa forma, o saber do terapeuta é local e contextualizado. O cliente é especialista no conteúdo, nos significados e nas vivências, enquanto o terapeuta é especialista no processo, no ato de coordenar o processo conversacional (Anderson \& Goolishian, 1998; Grandesso, 2000). Chen et al. (1998) apontam que esse posicionamento, por parte do terapeuta, honra o conhecimento do cliente e o convida à reflexividade, promovendo uma sensação de competência e de autoeficácia. Dessa forma, as autoras sistematizam o processo de não-saber dividindo-o em três procedimentos: substituindo suposiçóes por curiosidade, fazendo perguntas 
curiosas para saber um pouco mais sobre o que foi dito ou sobre o que ainda não é sabido; imaginando possibilidades, quando o terapeuta não encontra exceçóes no relato do cliente, ele pode imaginar e perguntar sobre um suposto resultado; e convidando os membros para reflexividade, convidando-os a observarem suas próprias percepçôes, açôes ou significados que formam a sua experiência.

Por fim, as autoras apresentam o princípio da "internalização do senso pessoal de agenciamento" dos clientes, desenvolvido inicialmente por White e Epston (1990), juntamente com a externalização do problema. Para esses autores, além de coisificar e personificar o problema, o objetivo dessa intervenção é construir com o paciente o sentido de que ele é agente ativo nos processos de significação e ressignificação de sua vida. Dessa forma, as pessoas vão internalizando essas conquistas realizadas como parte de sua identidade, o que lhes dá maior autonomia. Chen et al. (1998) apontam que este processo pode ser realizado por meio de cinco procedimentos: 1) a atribuiçáo de intencionalidade positiva, possibilitando que o cliente modifique a forma como se percebe, adquirindo um senso de agenciamento pessoal para mudança; 2) legitimando sentimentos, a partir da validação das emoções humanas, para que os sentimentos sejam utilizados com o intuito de desafiar os problemas; 3) colocando os membros como agentes ativos ao convidá-los a reformularem sua autonarrativa e responsabilizá-los pela dificuldade vivenciada em determinado contexto a partir de uma escolha de ação; 4) creditando influência ambiental, o que aumenta a capacidade do cliente para mudança ao perceber que seus comportamentos têm sido aprendidos do meio ambiente e que seus problemas de comportamento não são frutos de sua personalidade e 5) pontuando competências, ao destacar sinais de competência que foram negligenciados pelo cliente, que pode ter se descrito anteriormente como uma pessoa incompetente ou confusa.

Esses diversos princípios e os procedimentos que os operacionalizam mostram que a redação da carta é carregada de propósito e intenção por parte do terapeuta, que é quem escolhe atentamente quais aspectos destacar do relato do cliente e do processo terapêutico de forma a criar condiçóes para que novas mudanças se efetuem. A carta, como documento clínico, deixa de ser uma representação formal e burocrática do que aconteceu para ser um recurso de construção da mudança.

\section{Recomendaçóes práticas para a escrita das cartas}

Além desses princípios gerais, há uma série de recomendaçóes práticas referentes ao cotidiano da utilização das cartas e ao estilo da escrita (construçóes gra- 
maticais, tom, perguntas típicas). Essas recomendações, ao invés de serem tomadas como normas técnicas a serem seguidas pelo terapeuta, constituem cuidados complementares que podem potencializar a criatividade do terapeuta e, de forma respeitosa, promover a parceria terapêutica.

Em relação ao cotidiano do uso das cartas, elas podem ser usadas de forma contínua no processo terapêutico, a cada sessão, ou de forma pontual, dependendo dos tipos e objetivos da carta e das intenções do terapeuta. Seu uso sempre deve ser negociado com o paciente, o qual deve aceitar quando e para quem se envia a carta. Assim, White (1995) sugere que a carta não deve ser imposta ao cliente e que ele deve querer recebê-la, sabendo que esta faz parte do trabalho. Perguntas como "Com quem você mora?", "Você teria como guardar a carta?", "O documento ficará acessível sempre que você precisar?" são importantes para garantir a confidencialidade e a disponibilidade do documento. É também importante que o terapeuta antecipe algumas outras questóes, tais como os sentimentos que poderão surgir com a leitura da carta, para que a ação não fique comprometida e o terapeuta possa cuidar junto ao paciente de possíveis preocupações.

Apesar de parecer exigir mais tempo do terapeuta quando de seu uso contínuo, o uso da carta como documento clínico pode, na prática, tornar mais útil o tempo gasto com o registro administrativo dos atendimentos. Chen et al. (1998) apontam que psicólogos gastam um tempo importante fazendo anotaçóes em prontuários e propóem, assim, que elas se tornem um instrumento de intervenção em que a história do cliente na terapia é escrita em conjunto, em um processo de negociação, por meio das cartas. Assim, os relatos de sessáo podem ser escritos pelo terapeuta, lidos juntamente com o cliente na sessão seguinte e corrigidos por ambos, se necessário, em uma postura de respeito e legitimação à história da pessoa.

No que se refere à redação das cartas, White e Epston (1990) sugerem ainda que a carta, diferentemente da linguagem diagnóstica reservada aos prontuários, utilize a própria linguagem de quem conta a história, inclusive com a utilização de suas próprias metáforas, o que gera um reconhecimento da pessoa ao ler o escrito. Além disso, para que a carta seja escrita é necessário que o terapeuta se coloque em um lugar de legitimar as pessoas e o que é falado, retomando o que foi dito na sessão e buscando refletir sobre os acontecimentos.

Quanto ao uso dos verbos, Freeman et al. (2001, p. 168) propóem que se privilegiem as formas reflexivas, que "colocam o sujeito e o objeto em uma relação 'agente' onde normalmente não existe", auxiliando que a pessoa se perceba melhor por si mesma. $\mathrm{O}$ uso do gerúndio compóe o documento terapêutico, já 
que ele dá uma sensação de progresso e movimento. Por fim, os autores ressaltam o uso do subjuntivo, que amplia as possibilidades de respostas, ao invés de restringi-las a "sim" ou "não".

Moules (2000) enfatiza a importância do tom para escrever as cartas. Para a autora, o tom está conectado com a sintonia da palavra, que deve ser condizente com a relação entre o terapeuta e o cliente. As palavras carregam consigo melodias, cadências e entonações que devem respeitar as interações anteriores. Atenção particular deve ser dada à linguagem utilizada, que convida a múltiplas interpretaçóes e possibilidades.

Freedman e Combs (1996) chamam a atenção para o uso de perguntas nas cartas, que ao terminarem com uma reflexão permitem novas e múltiplas perspectivas. Apresentam cinco categorias de perguntas que auxiliam os terapeutas a organizar os pensamentos que podem ser utilizadas para a escrita da carta e apontam que essas categorias são fluidas e correspondem às intençóes do terapeuta nas questôes feitas. Entre as categorias, destacam-se: questóes desconstrutivas, questôes que abrem espaço, questôes preferíveis, questóes que desenvolvem histórias e questôes de significado.

As "questóes desconstrutivas" auxiliam as pessoas a perceberem suas histórias de diferentes perspectivas. Geralmente, são questóes que "encorajam as pessoas a situar suas narrativas em amplos sistemas, e através dos tempos" (Freedman $\&$ Combs, 1996, p. 120), envolvendo conversas ao redor de crenças problemáticas, práticas, sentimentos e atitudes. Nesse contexto, são feitas perguntas a respeito da história do relacionamento da pessoa com essas crenças. O impacto do problema na vida das pessoas e das relações é investigado, assim como a influência do contexto, as inter-relaçóes e as táticas e estratégias existentes.

As "questôes que abrem espaço" são utilizadas para construir acontecimentos extraordinários. O acontecimento extraordinário é uma ideia desenvolvida por White e Epston (1990) a partir do entendimento de que os aspectos da nossa experiência vivida que se tornam mais significativos são aqueles altamente selecionados e narrados, considerados narrativas dominantes. Como grande parte dos acontecimentos está fora dessa história dominante, eles não adquirem significado, mas possuem alto potencial para significação e, em circunstâncias favoráveis, podem ser constituídos como "acontecimentos extraordinários" ou "exceçóes". Dessa maneira, cada pergunta desenvolvida no documento terapêutico pode resultar na possível presença de uma abertura que levará a uma história alternativa. Nessa categoria, as perguntas englobam a busca por exceçóes, questóes de experiências hipotéticas, busca por diferentes pontos de vista e diferentes contextos, assim como questóes que abarcam diferentes tempos de vida da pessoa. 
Já as "questóes preferíveis" podem ser feitas frequentemente pelo terapeuta, para que o cliente tenha a noção de que a direção ou o significado que as experiências estão tomando são preferíveis às histórias problemáticas. As pessoas são convidadas a justificar suas escolhas e descrever suas motivaçóes, tendo a oportunidade de clarear e elaborar suas direçôes preferenciais de vida, identidades e valores.

Quando o espaço da conversação já foi aberto o bastante para revelar os caminhos preferíveis pelo cliente, pode-se fazer "questóes que desenvolvem histórias" com o intuito de convidar as pessoas a serem reautoras de suas narrativas. $\mathrm{O}$ intuito é que elas entrem em contato com o processo e os detalhes de sua experiência, que será "conectada a um calendário, para um contexto particular e para outras pessoas. Dessa maneira, um evento é expandido no espaço e no tempo, é habitado, e é revivido de forma detalhada" (Freedman \& Combs, 1996, p. 131).

Por fim, os autores descrevem as "questóes de significado", por meio das quais as pessoas são convidadas a considerar aspectos diferentes de suas histórias, delas mesmas e de seus relacionamentos, o que enriquece a nova narrativa em processo de desenvolvimento. Conversa-se sobre "qualidades pessoais, características dos relacionamentos, motivação, esperança, objetivos, valores, crenças, conhecimento e aprendizagens pessoais que as pessoas obtêm a partir de suas narrativas em desenvolvimento" (Freedman \& Combs, 1996, p. 137).

Essas categorias de perguntas estão sintonizadas com os princípios apresentados por Chen et al. (1998) e constituem recursos práticos para promovê-los, permitindo ao terapeuta uma visão clara sobre formas possíveis de alcançá-los no processo de redação das cartas por meio da seleção e construção das perguntas. Esses tipos de questóes constituem um panorama amplo a partir do qual o terapeuta deve criar as formas mais adequadas e sensíveis à relação terapêutica estabelecida com cada cliente em cada momento do processo terapêutico.

\section{Consideraçóes finais}

As cartas terapêuticas podem ser escritas por terapeutas orientados por diferentes abordagens teóricas, contudo elas ganham significado neste artigo a partir de uma epistemologia narrativa. Assim, os princípios e as recomendaçóes práticas apresentados auxiliam o processo de escrita das cartas terapêuticas, sendo um importante recurso de sustentação para a criação do terapeuta, auxiliando-o a atingir os objetivos propostos. Entretanto, para que possa ser utilizado, é importante que o profissional se familiarize com as propostas teóricas e a abordagem terapêutica 
que o originaram. Fora do contexto narrativo, as cartas podem ser entendidas em uma perspectiva normativa, de controle e regulação, voltado a um foco específico, a partir de critérios estabelecidos pelo terapeuta, distorcendo a busca de liberação do cliente em relaçáo a narrativas dominantes e que náo legitimam a experiência vivida por ele, tal como buscado pela Terapia Narrativa.

É nesse contexto teórico que a as cartas trazem uma contribuição ética particular. Por serem escritas de maneira respeitosa, de forma transparente e cuidadosa, em cocolaboração e concordância com o cliente a quem as cartas se referem, elas exercem um papel ético à medida que reconhecem o crescimento do paciente, contando de sua evolução. Assim, elas náo são calcadas em procedimentos administrativos, baseadas apenas no ponto de vista do terapeuta, pois pautam-se na relação do terapeuta com o cliente e em como essa é construída. A verdade não está no terapeuta e no que ele relata, mas na relação e em como ela constrói histórias.

Esse modo de pensar e usar as cartas é o que permite que elas sejam percebidas pelo cliente de forma enriquecedora. Segundo White e Epston (1990), em pesquisas junto a clientes que receberam cartas, estas foram avaliadas como produzindo efeitos equivalentes ao trabalho terapêutico de 3 a 10 sessôes. Contudo, não há outras investigaçóes empíricas relatadas na literatura que nos ajudem a compreender melhor o uso e o significado de tal instrumento.

O uso de cartas terapêuticas no contexto brasileiro, tal como descrito neste artigo, está apenas em seu início. É preciso, então, investigarmos como os clientes recebem as cartas, quais efeitos elas geram no processo terapêutico, que fatores de nossa cultura facilitam ou dificultam o seu uso e que possíveis mudanças deveriam ser incorporadas a essa prática terapêutica. Acreditamos que, apesar dos desafios aí presentes, há um campo fértil para a prática e pesquisa em psicoterapia, sendo uma oportunidade para a criação de novos recursos terapêuticos, especificamente, e de reflexão sobre as contribuiçóes da Terapia Narrativa no contexto social e cultural brasileiro.

\section{Referências}

Anderson, H. \& Goolishian, H. (1998). O cliente é o especialista: a abordagem terapêutica do não saber. In: S. McNamee \& K. Gergen (orgs.). A terapia como construção social (pp. 34-49). Porto Alegre: Artes Médicas.

Augusta-Scott, T. (2007). Letters from prision: re-authoring identity with men who have perpetratted sexual violence. In: C. Brown \& T. Augusta-Scott (edits.). Narrative therapy: making meaning, making lives (pp. 251-268). Thousand Oaks, CA: Sage. 
Brouwers, M. (2001). Bulimia and the relationship with food: a letters-to-food technique. Journal of Counseling \& Development, 73, 220-222.

Chen, M., Noosbond, J. P. \& Bruce, M. A. (1998). Therapeutic document in group counseling: an active change agent. Journal of Counseling \& Development, 76, 404-411.

Couper, J. \& Harari, E. (2004). Use of psychiatric consultation letter as a therapeutic tool. Australasian Psychiatry, 12(4), 365-368.

Davidson, H. \& Birmingham, C. L. (2001). Letter writing as a therapeutic tool. Eating Weight Disorder, 6, 40-44.

Erlingsson, C. (2009). Undergraduate nursing students writing therapeutic letters to families: an educational strategy. Journal of Family Nursing, 15(1), 83-101.

Esterling, B. A., L’Abate, L., Murray, E. J., \& Pennebaker, J. W. (1999). Empirical foundations for writing in prevention and psychotherapy: mental and physical health outcomes. Clinical Psychology Review, 19(1), 79-96.

Fredman, J. \& Combs, G. (1996). Narrative therapy: the social construction of preferred realities. New York: W. W. Norton.

Freeman, J., Epston, D. \& Labovits, D. (2001). Terapia narrativa para niños: aproximación a los conflictos familiares a través del juego. Barcelona: Paidós.

Goldberg, D. (2000). "Emplotment": letter writing with troubled adolescents and their families. Clinical Child Psychology and Psychiatry, 5, 63-76.

Grandessso, M. (2000). Sobre a reconstrução do significado. São Paulo: Casa do Psicólogo.

Hunt, C., Schochet, I. \& King, R. (2005). The use of e-mail in the therapy process. Australian \& New Zealand Journal of Family Therapy, 26(1), 10-20.

Kress, V. E., Hoffman, R. \& Thomas, A. M. (2008). Letters from the future: the use of therapeutic letter writing in counseling sexual abuse survivors. Journal of Creativity in Mental Health, 3(2), 105-118.

Moules, N. J. (2000). Nursing on paper: the art and mystery of therapeutic letters in clinical work with families experiencing illness. (Tese de Doutorado, Faculty of Nursing, The University of Calgary, Alberta/Canadá).

Moules, N. J. (2003). Therapy on paper: therapeutic letters and the tone of relationship. Journal of Systemic Therapies, 22(1), 33-49.

Oliver, M., Nelson, K. W., Cade, R. \& Cueva, C. (2007). Therapeutic letter writing from school counselors to students, parents and teachers. The Professional School Counseling Journal, 5(5), 10-513.

Paré, D. A. \& Rombach, M. A. M. (2003). Therapeutic letters to young persons (pp. 199203). In: C. F. Sori \& L. Hecker (orgs.). The therapists' notebook for children and adolescents. Nova York: Haworth Press.

Payne, M. (2006). Narrative therapy: an introduction for counselors. London: Sage.

Pyle, N. R. (2004). Letters about letters: client's written reflections on therapeutic letters. Dissertação de Mestrado, Faculty of Education, Memorial University of Newfoundland, Canadá. 
Pyle, N. R. (2009). Therapeutic letters as relationally responsive practice. Journal of Family Nursing, 15(1), 65-82.

Rombach, M. A. M. (2003). An invitation to therapeutic letter writing. Journal of Systemic Therapies, 22(1), 15-32.

Thomas, P. (1998). Writing letters to patients. Psychiatric Bulletin, 22, 542-545.

Tubman, J. G., Montgomery, M. J. \& Wagner, E. E. (2001). Letter writing as a tool to increase client motivation to change: application to an inpatient crisis unit. Journal of Mental Health Counseling, 23, 295-311.

Vidgen, A. \& Williams, R. (2001). Letter-writing practices in a child and family service. Journal of Family Therapy, 2, 317-326.

White, M. (1995). Re-authoring lives: interviews and essays. Adelaide: Dulwich Centre.

White, M. (2007). Maps of narrative practice. New York: W.W. Norton \& Company.

White, M. \& Epston, D. (1990). Medios narrativos para fines terapéuticos. Barcelona: Paidós.

Wright, J. K. (2005). Writing therapy in brief workplace counselling. Counselling and Psychoterapy Research, 5(2), 111-119.

Yeung, F. K. C., Cheng, S. F. \& Chau, Y. Y. (2003). Uncle long legs' letter box; a letter counseling service for children in Hong Kong. Child and Adolescent Social Work Journal, 20(1), $37-51$.

\section{Notas}

${ }^{1}$ Considerando o foco desse artigo, não realizaremos uma apresentação mais ampla da Terapia Narrativa. Para aqueles interessados, sugerimos a leitura de White e Epston (1990) e White (2007).

Recebido em 25 de maio de 2011 Aceito para publicação em 15 de novembro de 2011 